\title{
Environmental Contamination with Cyclophosphamide, Ifosfamide, and Methotrexate: A Study of 51 Canadian Centres
}

\author{
Alexia Janes, Cynthia Tanguay, Nicolas J Caron, and Jean-François Bussières
}

\begin{abstract}
Background: Occupational exposure to hazardous drugs may lead to adverse reproductive effects. There is no safe exposure limit for health care professionals.

Objectives: To monitor levels of cyclophosphamide, ifosfamide, and methotrexate contamination in oncology pharmacy and patient care areas in Canadian health care institutions.

Methods: The study was conducted in 2014. Hospitals with at least 50 acute care beds were invited to participate. At each participating centre, 12 standardized sites ( 6 in pharmacy areas and 6 in patient care areas) were sampled. The samples were analyzed for the presence of cyclophosphamide, ifosfamide, and methotrexate by ultra-performance liquid chromatography tandem mass spectrometry technology. The limits of detection were $0.36 \mathrm{pg} / \mathrm{cm}^{2}$ for cyclophosphamide, $0.95 \mathrm{pg} / \mathrm{cm}^{2}$ for ifosfamide, and $0.97 \mathrm{pg} / \mathrm{cm}^{2}$ for methotrexate. Descriptive statistical analyses were performed to determine the median, 75th percentile, and maximum levels.

Results: Fifty-one hospitals participated in this descriptive study, and a total of 584 samples were quantified. Overall, 294 (50\%) of the samples were positive for cyclophosphamide, 125 (21\%) for ifosfamide, and 54 (9\%) for methotrexate. The most frequently contaminated sampling sites in pharmacy areas were the front grille inside the hood and the floor in front of the hood and, in patient care areas, the armrest and outpatient clinic counter. The 75th percentiles for surface concentration were 10.8 $\mathrm{pg} / \mathrm{cm}^{2}$ for cyclophosphamide, $1.59 \mathrm{pg} / \mathrm{cm}^{2}$ for ifosfamide, and below the limit of detection for methotrexate.

Conclusions: Relative to 3 other multicentre studies conducted in Quebec over the past few years, the proportion of positive samples remained constant. Nonetheless, the 75 th percentile surface concentration of antineoplastic drugs has been decreasing and seems to have reached a plateau. Local (country-specific or region-specific) and attainable goals for surface contamination with hazardous drugs should be set annually, so long as no health-based limit is known.
\end{abstract}

Keywords: occupational exposure, environmental monitoring, antineoplastic agents, cyclophosphamide, ifosfamide, methotrexate

\section{Can J Hosp Pharm. 2015;68(4):279-89}

\section{RÉSUMÉ}

Contexte : L'exposition professionnelle à des médicaments dangereux peut causer des effets indésirables sur la reproduction. Aucune limite d'exposition sécuritaire n'est établie pour les professionnels de la santé.

Objectifs : Évaluer les taux de cyclophosphamide, d'ifosfamide et de méthotrexate dans la pharmacie d'oncologie et dans les unités de soins des établissements de santé canadiens.

Méthodes : L'étude s'est déroulée en 2014. Les hôpitaux disposant d'au moins 50 lits de soins de courte durée ont été invités à participer. Dans chacun des établissements participants, des échantillons ont été prélevés dans 12 zones prédéterminées : 6 dans les pharmacies et 6 dans les unités de soins. On a ensuite analysé les échantillons par chromatographie liquide à très haute performance couplée à la spectrométrie de masse en tandem afin de détecter la présence de cyclophosphamide, d'ifosfamide et de méthotrexate. Le seuil de détection était de $0,36 \mathrm{pg} / \mathrm{cm}^{2}$ pour la cyclophosphamide, de $0,95 \mathrm{pg} / \mathrm{cm}^{2}$ pour l'ifosfamide et de $0,97 \mathrm{pg} / \mathrm{cm}^{2}$ pour le méthotrexate. Des analyses statistiques descriptives ont été effectuées afin de déterminer la médiane, le $75^{\mathrm{e}}$ percentile et les taux maximums.

Résultats : Au total, 51 hôpitaux ont participé à cette étude descriptive et 584 échantillons ont été quantifiés. Dans l'ensemble, 294 (50\%) échantillons étaient positifs pour la cyclophosphamide, 125 (21\%) pour l'ifosfamide et $54(9 \%)$ pour le méthotrexate. Les zones les plus fréquemment contaminées étaient : en pharmacie, la grille avant dans la hotte et le sol devant la hotte; dans les unités de soins, les accoudoirs et le comptoir des cliniques de consultation externe. Le 75e percentile de la concentration de surface était de $10,8 \mathrm{pg} / \mathrm{cm}^{2}$ pour la cyclophosphamide, $1,59 \mathrm{pg} / \mathrm{cm}^{2}$ pour l'ifosfamide et sous le seuil de détection pour le méthotrexate.

Conclusions : Comparativement à trois autres études multicentriques menées au Québec au cours des dernières années, la proportion de prélèvements positifs demeure la même. Toutefois, le $75^{\mathrm{e}}$ percentile de la concentration de surface d'antinéoplasiques a diminué et semble avoir atteint un plateau. Des objectifs locaux (pour le pays ou selon les régions) et réalisables de contamination de surface par des médicaments dangereux devraient être établis chaque année, et ce, tant qu'aucune limite fondée sur les critères liés à la santé ne sera pas déterminée.

Mots clés : exposition professionnelle, surveillance environnementale, antinéoplasiques, cyclophosphamide, ifosfamide, méthotrexate 


\section{INTRODUCTION}

$\mathrm{O}$ ccupational exposure to hazardous drugs can lead to adverse effects on health care workers, including nurses, pharmacists, pharmacy technicians, and support workers. ${ }^{1}$ In particular, exposure to hazardous drugs has been shown to lead to adverse reproductive outcomes. ${ }^{2,3}$ To raise awareness about this issue, the US National Institute for Occupational Safety and Health (NIOSH) published an alert on the prevention of occupational exposure to hazardous drugs in $2004 .{ }^{4}$ Since then, $\mathrm{NIOSH}$ has been updating its list of hazardous drugs every 2 years. In addition to antineoplastic drugs, other drugs that are considered hazardous include immunosuppressants, antipsychotics, antidepressants, and hormones. In the $2014 \mathrm{NIOSH}$ list of hazardous drugs, the majority of drugs (97/184 [53\%]) are antineoplastic drugs. ${ }^{5}$

Following the $2004 \mathrm{NIOSH}$ alert, ${ }^{4}$ many organizations reviewed their guidelines for the safe handling of hazardous drugs. For instance, the American Society of Health-System Pharmacists published new guidelines in $2006 .{ }^{6}$ The United States Pharmacopeial Convention is also developing a new guideline (USP General Chapter $<800>$ ) that will contain specific requirements for compounding both antineoplastic and nonantineoplastic hazardous drugs. ${ }^{7}$ In Quebec, the Association paritaire pour la santé et la sécurité du travail du secteur des affaires sociales (a "joint, sector-based association dedicated to promoting occupational health and safety prevention and supporting health and social service sector workers and institutions") published a safe handling guide in $2008 .^{8}$ In addition, the Ordre des pharmaciens du Québec recently published a new guideline for compounding sterile hazardous drugs. ${ }^{9}$ This guideline recommends that chemical contamination on work surfaces be assessed twice per year.

Since 2008, the authors' group has performed 3 multicentre studies of environmental contamination in Quebec hospitals. ${ }^{10-12}$ For a more recent investigation, reported here, the scope of study was expanded to include Canadian centres outside Quebec. The aim of this study was to monitor environmental contamination with cyclophosphamide, ifosfamide, and methotrexate in oncology pharmacy and patient care areas in Canadian hospitals. The secondary objective was to describe temporal trends.

\section{METHODS}

\section{Participating Hospitals}

Directors of pharmacy departments in Canadian hospitals with at least 50 acute care beds were contacted by e-mail. Any hospital that handled one or more of the 3 target antineoplastic drugs was eligible to participate in the study. Pharmacy directors in Quebec hospitals $(n=58)$ were contacted on December 20, 2013, and a reminder was sent on January 10, 2014. Pharmacy directors in hospitals in other provinces $(n=137)$ were contacted on January 10, 2014 (there was no systematic follow-up for potential respondents outside Quebec).

Each participating hospital was expected to apply local policies and procedures for compounding, administration, surface cleaning, waste management, and other aspects of drug handling. All participating hospitals were equipped with laminar air flow cabinets in the pharmacy, for sterile compounding. Each hospital assumed the cost of analysis for its own samples. Participants were asked whether they were using a closed-system transfer device (CSTD) for preparing antineoplastic drugs in the pharmacy (i.e., "a drug transfer device that mechanically prohibits the transfer of environmental contaminants into the system and the escape of hazardous drug or vapor concentrations outside the system"). Participants were also asked whether they removed the outer packaging of antineoplastic drugs in the pharmacy after receipt and whether they cleaned the vials of antineoplastic drugs in the pharmacy after receipt. After the study was completed, each participating centre received a report comparing its results with global results from all participating centres. The authors' research group previously set the overall 75 th percentile of surface concentration as a goal for every participating centre; after the conclusion of the study, centres were encouraged to target sampling sites with values above this goal for corrective measures.

\section{Sampling Technique}

The sampling technique was described previously. ${ }^{10-12}$ Twelve standardized measurement sites, 6 in pharmacy areas and 6 in patient care areas, were selected for sampling (Table 1). These sites were identical with those targeted in the 2008-2010, 2012, and 2013 studies. ${ }^{10-12}$ Each participating hospital was given a description and photographs of the standardized sampling sites. The photographs provided were taken at the investigators' hospital. Each participating hospital was also asked to provide a picture of the actual sites used for sampling. Samples were collected by one research assistant (A.J.) from the research team (for nearby hospitals) or by a trained employee from the participating hospital (for remote hospitals). A video of the sampling technique was provided for training of employees. For each sample, a standardized surface of about $600 \mathrm{~cm}^{2}(20 \mathrm{~cm} \times$ $30 \mathrm{~cm}$ ) was sampled with one $6 \mathrm{~cm} \times 8 \mathrm{~cm}$ Wypall X60 wipe (Kimberly Clark Professional, Newton Square, Pennsylvania). The wipe was moistened with $1 \mathrm{~mL}$ of sampling solution $(10 \%$ methanol and $90 \% 5 \mathrm{mmol} / \mathrm{L}$ ammonium acetate). Sites were sampled at the end of a workday or in the morning, before surfaces were washed. The sampling technique, an adaptation of the technique described by Larson and others, ${ }^{13}$ was developed by the Institut national de santé publique du Québec.

\section{Analytical Procedure}

Sampling wipes were stored at a temperature between $2^{\circ} \mathrm{C}$ and $8^{\circ} \mathrm{C}$ in $50-\mathrm{mL}$ polypropylene tubes. Before analysis, $10 \mathrm{~mL}$ 
This single copy is for your personal, non-commercial use only.

For permission to reprint multiple copies or to order presentation-ready copies for distribution, contact CJHP at cjhpedit@cshp.ca

\section{Table 1. Description of 12 Standardized Sites to be Sampled at Each Centre}

\begin{tabular}{|c|c|}
\hline Sampling Site & Description \\
\hline \multicolumn{2}{|l|}{ Pharmacy areas } \\
\hline Shipment reception counter & Counter used for receiving shipments and for unpacking antineoplastic drugs \\
\hline Storage shelf or bin & Shelf or bin used for storage of antineoplastic drugs \\
\hline Front grille inside hood & $\begin{array}{l}\text { Grille located in the front of the main hood (biological safety cabinet) used for compounding } \\
\text { antineoplastic drugs }\end{array}$ \\
\hline Floor in front of hood & Floor in front of the main hood used for compounding antineoplastic drugs \\
\hline $\begin{array}{l}\text { Service hatch or counter for } \\
\text { postpreparation validation }\end{array}$ & $\begin{array}{l}\text { Service hatch used to transfer drugs from the compounding room to the postpreparation } \\
\text { validation area or counter used by pharmacy personnel for postpreparation validation }\end{array}$ \\
\hline Tray used for drug delivery & Tray or container used to deliver antineoplastic drugs to patient care areas after their preparation \\
\hline \multicolumn{2}{|r|}{ (1) } \\
\hline Storage shelf or bin & Shelf or bin used for storage of antineoplastic drugs \\
\hline $\begin{array}{l}\text { Counter used for priming } \\
\text { and validation }\end{array}$ & $\begin{array}{l}\text { Counter used for priming tubing for antineoplastic drugs or for the nurse's final validation of } \\
\text { compounded syringes before administration of drugs to patients; if no priming counter, a counter } \\
\text { where the drugs are stored before administration. }\end{array}$ \\
\hline Armrest & $\begin{array}{l}\text { Armrest (on a chair or elsewhere) where a patient would put his or her arm during administration } \\
\text { of a antineoplastic drug from a peripheral line }\end{array}$ \\
\hline Counter in patient's room & $\begin{array}{l}\text { Counter (or table) in a patient's room where drugs and related devices are placed during drug } \\
\text { administration, in a room where at least one dose of cyclophosphamide, ifosfamide, or } \\
\text { methotrexate was given in the 12-h period before sampling }\end{array}$ \\
\hline Counter in outpatient clinic & $\begin{array}{l}\text { Counter (or table) in an outpatient clinic where drugs and related devices are placed during drug } \\
\text { administration, in a location where at least one dose of cyclophosphamide, ifosfamide, or } \\
\text { methotrexate was given in the 12-h period before sampling }\end{array}$ \\
\hline $\begin{array}{l}\text { Exterior surface of antineo- } \\
\text { plastic drug container }\end{array}$ & Exterior surface of syringe or bag containing compounded drug \\
\hline
\end{tabular}

of extracting solution and internal standards were added to each tube. Each tube was mechanically stirred for $10 \mathrm{~min}$, and an aliquot of the solution was removed for analysis. For each sample, 3 antineoplastic drugs (cyclophosphamide, ifosfamide, methotrexate) were quantified by ultra-performance liquid chromatography tandem mass spectrometry (Acquity UPLC chromatographic system coupled with Xevo TQ-S tandem mass spectrometer; Waters, Milford, Massachusetts). Chromatography was carried out on a C18 Acquity UPLC BEH column $(2.1 \times$ $50 \mathrm{~mm}, 1.7 \mu \mathrm{m}$; Waters, Milford, Massachusetts) with a gradient from $10 / 90$ to $60 / 40$ of methanol / $5 \mathrm{mmol} / \mathrm{L}$ ammonium acetate over $2 \mathrm{~min}$. Overall, mean recovery from surfaces was $79 \%$, and the intra-assay coefficient of variation was $22 \%$. Recovery from surfaces ranged from $67 \%$ to $89 \%$ for stainless steel (coefficient of variation 5\%-8\%), from $79 \%$ to $102 \%$ for melamine (coefficient of variation 1\%-3\%), from $89 \%$ to $92 \%$ for plastic (coefficient of variation 4\%-6\%), and from $37 \%$ to $82 \%$ for linoleum (coefficient of variation 7\%-22\%).

Results expressed in nanograms per millilitre $(\mathrm{ng} / \mathrm{mL})$ were converted to nanograms per square centimetre $\left(\mathrm{ng} / \mathrm{cm}^{2}\right)$. These values were then multiplied by 11 (the dilution factor) and divided by $600 \mathrm{~cm}^{2}$ (the surface area sampled) to obtain the final results, which were expressed in picograms per square centimetre $\left(\mathrm{pg} / \mathrm{cm}^{2}\right)$. The limit of detection was $0.36 \mathrm{pg} / \mathrm{cm}^{2}(19.8 \mathrm{pg} / \mathrm{mL})$ for cyclophosphamide, $0.95 \mathrm{pg} / \mathrm{cm}^{2}(52 \mathrm{pg} / \mathrm{mL})$ for ifosfamide, and $0.97 \mathrm{pg} / \mathrm{cm}^{2}(53 \mathrm{pg} / \mathrm{mL})$ for methotrexate. The limit of quantification was $1.21 \mathrm{pg} / \mathrm{cm}^{2}(65.9 \mathrm{pg} / \mathrm{mL})$ for cyclophosphamide, $3.17 \mathrm{pg} / \mathrm{cm}^{2}$ (173 pg/mL) for ifosfamide, and 3.25 $\mathrm{pg} / \mathrm{cm}^{2}(177 \mathrm{pg} / \mathrm{mL})$ for methotrexate. The limit of detection was used as the reporting limit.

\section{Data Analysis}

The proportion of positive samples was calculated. A sample was considered positive for a particular drug if the value was above the limit of detection. Descriptive statistical analyses (minimum, median, 75th percentile, 90th percentile, maximum) were carried out. For calculations, concentrations that fell between the limit of detection and the limit of quantification were assigned a value corresponding to the limit of quantification divided by $2,{ }^{14}$ and concentrations that fell below the limit of detection were assigned a value corresponding to the limit of detection divided by $2 .{ }^{15}$

Results from the hospitals that participated in the 3 earlier studies ${ }^{10-12}$ and the current study were used for comparisons over time.

Subanalyses were performed according to hospitals' working practices, i.e., use of a CSTD, removal of packaging, and cleaning of vials after initial receipt. The effect of CSTD use was evaluated for pharmacy sampling sites corresponding to steps performed during and after compounding (i.e., hood, floor, service hatch, delivery tray). The effect of packaging removal and cleaning of vials was evaluated for pharmacy sampling sites corresponding to steps performed after receipt of drugs (i.e., storage shelf, hood, floor, service hatch, delivery tray). Results were compared with a Kolmogorov-Smirnov test for 2 unpaired samples. A $p$ value less than 0.05 was considered significant. For these subanalyses, only the results for cyclophosphamide contamination were used, as they were deemed representative of the current situation; there was too little surface contamination with ifosfamide and methotrexate to allow similar subanalyses. 


\section{RESULTS}

\section{Participating Hospitals}

A total of 51 Canadian hospitals participated in this study: 34 (59\%) of the 58 Quebec hospitals and 17 (12\%) of the 137 centres from other Canadian provinces. The respondents from provinces other than Quebec were from Manitoba, New Brunswick, Nova Scotia, Ontario, and Prince Edward Island.

Two-thirds of the participating centres (34/51 [67\%]) were teaching hospitals. Nearly all participating centres (49/51 [96\%]) provided information about their working practices. Of these, 12 (24\%) used a CSTD: ChemoClave System (ICU Medical Inc, San Clemente, California) $(n=6)$, PhaSeal (Becton, Dickinson and Company, Franklin Lakes, New Jersey) $(n=3)$, Chemo Dispensing Pin (B Braun Medical Inc, Bethlehem, Pennsylvania) $(n=1)$, unspecified $(n=2)$. Greater proportions of these hospitals removed the outer packaging after receipt (29/49 [59\%]) and cleaned the vials after receipt (28/49 [57\%]). Among the 49 respondents providing information about working practices, 7 (14\%) used a CSTD, removed outer packaging, and cleaned vials after receipt.

\section{Environmental Contamination with Antineoplastic Drugs}

A total of 584 samples were collected between February and September 2014 (303 from pharmacy areas and 281 from patient care areas). The median number of sites per hospital with at least one positive sample for any drug was 7 (range 1-11). All participating hospitals had at least 1 positive sample for at least 1 of the 3 antineoplastic drugs evaluated (cyclophosphamide, ifosfamide, or methotrexate).

Overall, 50\% (294/584) of the samples were positive for cyclophosphamide, 21\% (125/584) were positive for ifosfamide, and $9 \%(54 / 584)$ were positive for methotrexate (Table 2). For 6 sampling sites - the storage shelf or bin in the pharmacy, the front grille inside the hood, the floor in front of the hood, the armrest, a counter in the patient's room, and a counter used for priming - at least half of the samples were positive for cyclophosphamide.

The overall 75th percentiles for drug concentration were $10.8 \mathrm{pg} / \mathrm{cm}^{2}$ for cyclophosphamide, $1.59 \mathrm{pg} / \mathrm{cm}^{2}$ for ifosfamide, and below the limit of detection for methotrexate (Table 3).

\section{Comparison of Hospitals in Quebec and the Rest of Canada}

Because participants in this study included centres located outside Quebec, the level of surface contamination was compared according to geographic location. Surface contamination with cyclophosphamide was similar in pharmacy areas in hospitals inside and outside Quebec (Figure 1). However, contamination with cyclophosphamide was higher in patient care areas from Quebec hospitals, which resulted in higher overall contamination Table 2. Proportion of Samples Testing Positive* for Antineoplastic Drugs in Pharmacy and Patient Care Areas
in 51 Canadian Hospitals (Sampling in 2014)

\begin{tabular}{|c|c|c|c|c|c|c|}
\hline \multirow{3}{*}{$\frac{\text { Sampling Site }}{\text { Pharmacy areas }}$} & \multicolumn{6}{|c|}{ Drug; No. (\%) of Samples with Positive Result } \\
\hline & \multicolumn{2}{|c|}{ Cyclophosphamide } & \multicolumn{2}{|c|}{ Ifosfamide } & \multicolumn{2}{|c|}{ Methotrexate } \\
\hline & & & & & & \\
\hline Shipment reception counter $(n=50)$ & 9 & $(18)$ & 2 & (4) & 4 & (8) \\
\hline Storage shelf or bin $(n=50)$ & 25 & $(50)$ & 19 & (38) & 10 & $(20)$ \\
\hline Front grille inside hood $(n=51)$ & 42 & $(82)$ & 18 & (35) & 16 & (31) \\
\hline Floor in front of hood $(n=51)$ & 38 & (75) & 23 & $(45)$ & 9 & $(18)$ \\
\hline $\begin{array}{l}\text { Service hatch or counter for } \\
\text { postpreparation validation }(n=51)\end{array}$ & 17 & (33) & 10 & (20) & 1 & (2) \\
\hline Trays used for drug delivery $(n=50)$ & 13 & $(26)$ & 10 & $(20)$ & 4 & (8) \\
\hline Subotal $(n=303)$ & 144 & (48) & 82 & $(27)$ & 44 & $(15)$ \\
\hline \multicolumn{7}{|l|}{ Patient care areas } \\
\hline Storage shelf or bin $(n=50)$ & 17 & (34) & 6 & $(12)$ & 2 & (4) \\
\hline $\begin{array}{l}\text { Counter used for priming or } \\
\text { validation }(n=50)\end{array}$ & 28 & (56) & 4 & (8) & 3 & (6) \\
\hline Armrest $(n=47)$ & 43 & (91) & 15 & $(32)$ & 0 & (0) \\
\hline Counter in patient's room $(n=44)$ & 27 & $(61)$ & 11 & $(25)$ & 2 & (5) \\
\hline Outpatient clinic counter $(n=44)$ & 19 & $(43)$ & 2 & (5) & 1 & (2) \\
\hline $\begin{array}{l}\text { Exterior surface of antineoplastic } \\
\text { drug container }(n=46)\end{array}$ & 16 & (35) & 5 & $(11)$ & 2 & (4) \\
\hline Subtotal $(n=281)$ & 150 & $(53)$ & 43 & $(15)$ & 10 & (4) \\
\hline Overall total $(n=584)$ & 294 & (50) & 125 & (21) & 54 & (9) \\
\hline
\end{tabular}


(Figure 1). The most contaminated sites were the same for all Canadian centres.

\section{Trends from 2008-2010 to 2014}

Three similar studies were conducted in Quebec in 20082010, 2012, and 2013, with 25, 33, and 36 participating hospitals, respectively. ${ }^{10-12}$ Nineteen hospitals participated in all 4 studies. There was no difference in surface contamination between the 19 centres that participated in all 4 studies and the 51 centres that participated in the 2014 study (Figure 2). The proportion of positive samples remained constant over the years (Figure 2A), but the 75th percentile of cyclophosphamide surface concentration declined and reached a steady state in 2012 (Figure 2B).

It is relevant to mention that the limits of detection declined over the years, which may have limited comparisons among the 4 studies. To test this possibility, the proportion of positive samples was recalculated using the value for limit of detection that was in effect in the 2008-2010 study, which was higher than the current limit of detection. With this change, the proportion of positive samples still remained constant over the years (data not shown). Thus, we are confident that the trend as reported here is accurate and was not caused by a change in the limits of detection.

Table 3. Surface Contamination with Antineoplastic Drugs in Pharmacy and Patient Care Areas in 51 Canadian Hospitals (Sampling in 2014)

Drug; Concentration $\left(\mathrm{pg} / \mathrm{cm}^{2}\right)$ *

\begin{tabular}{|c|c|c|c|c|c|c|c|c|c|}
\hline \multirow[t]{2}{*}{ Sample Site } & \multicolumn{3}{|c|}{ Cyclophosphamide } & \multicolumn{3}{|c|}{ Ifosfamide } & \multicolumn{3}{|c|}{ Methotrexate } \\
\hline & 50th perc. & 75th perc. & Max & 50th perc. & 75th perc. & Max & 50th perc. & 75th perc. & Max \\
\hline \multicolumn{10}{|c|}{ Pharmacy areas } \\
\hline $\begin{array}{l}\text { Shipment } \\
\text { reception } \\
\text { counter }(n=50)\end{array}$ & $<\mathrm{LOD}$ & $<\mathrm{LOD}$ & 86.9 & $<L O D$ & $<L O D$ & 67.9 & $<L O D$ & $<L O D$ & 22.6 \\
\hline $\begin{array}{l}\text { Storage shelf } \\
(n=50)\end{array}$ & 0.600 & 3.91 & 298 & $<$ LOD & 3.69 & 202 & $<L O D$ & 1.46 & 451 \\
\hline $\begin{array}{l}\text { Front grille inside } \\
\text { hood }(n=51)\end{array}$ & 21.5 & 153.0 & 3200 & $<\mathrm{LOD}$ & 8.32 & 85100 & $<L O D$ & 3.36 & 1080 \\
\hline $\begin{array}{l}\text { Floor in front of } \\
\text { hood }(n=51)\end{array}$ & 12.7 & 67.6 & 555 & $<L O D$ & 9.42 & 455 & $<L O D$ & $<L O D$ & 13.0 \\
\hline $\begin{array}{l}\text { Service hatch or } \\
\text { counter for post- } \\
\text { preparation } \\
\text { validation } \\
(n=51)\end{array}$ & $<\mathrm{LOD}$ & 3.21 & 3850 & $<L O D$ & $<\mathrm{LOD}$ & 1050 & $<L O D$ & $<L O D$ & 4.46 \\
\hline $\begin{array}{l}\text { Trays used for } \\
\text { drug delivery } \\
(n=50)\end{array}$ & $<\mathrm{LOD}$ & 0.61 & 53.2 & $<L O D$ & $<\mathrm{LOD}$ & 15400 & $<L O D$ & $<L O D$ & 28.1 \\
\hline $\begin{array}{l}\text { Subtotal } \\
(n=303)\end{array}$ & 0.360 & 12.2 & 3850 & $<\mathrm{LOD}$ & 1.65 & 85100 & $<$ LOD & $<L O D$ & 1080 \\
\hline \multicolumn{10}{|l|}{ Patient care areas } \\
\hline $\begin{array}{l}\text { Storage shelf } \\
(n=50)\end{array}$ & $<L O D$ & 1.28 & 11430 & $<L O D$ & $<L O D$ & 47.8 & $<L O D$ & $<L O D$ & 52.1 \\
\hline $\begin{array}{l}\text { Counter used } \\
\text { for priming or } \\
\text { validation }(n=50)\end{array}$ & 0.6 & 4.77 & 82.3 & $<L O D$ & $<$ LOD & 23.6 & $<L O D$ & $<$ LOD & 13.3 \\
\hline Armrest ( $n=47)$ & 45.3 & 159 & 903 & $<\mathrm{LOD}$ & 5.75 & 1050 & $<\mathrm{LOD}$ & $<\mathrm{LOD}$ & $<\mathrm{LOD}$ \\
\hline $\begin{array}{l}\text { Patient room } \\
\text { counter }(n=44)\end{array}$ & 2.68 & 6.88 & 38.5 & $<L O D$ & $<\mathrm{LOD}$ & 512 & $<$ LOD & $<L O D$ & 1.62 \\
\hline $\begin{array}{l}\text { Outpatient clinic } \\
\text { counter }(n=44)\end{array}$ & $<L O D$ & 3.27 & 27.7 & $<L O D$ & $<\mathrm{LOD}$ & 35.7 & $<L O D$ & $<L O D$ & 10.0 \\
\hline $\begin{array}{l}\text { Exterior surface } \\
\text { of antineoplastic } \\
\text { drug container } \\
(n=46)\end{array}$ & 1.51 & 8.04 & 8290 & 2.15 & 3.97 & 233 & 2.19 & 4.05 & 249 \\
\hline Subtotal $(n=281)$ & 1.51 & 9.06 & 11400 & $<\mathrm{LOD}$ & 1.43 & 1050 & $<\mathrm{LOD}$ & $<\mathrm{LOD}$ & 249 \\
\hline $\begin{array}{l}\text { Overall total } \\
(n=584)\end{array}$ & 0.72 & 10.8 & 11400 & $<$ LOD & 1.59 & 85100 & $<$ LOD & $<$ LOD & 1080 \\
\hline
\end{tabular}




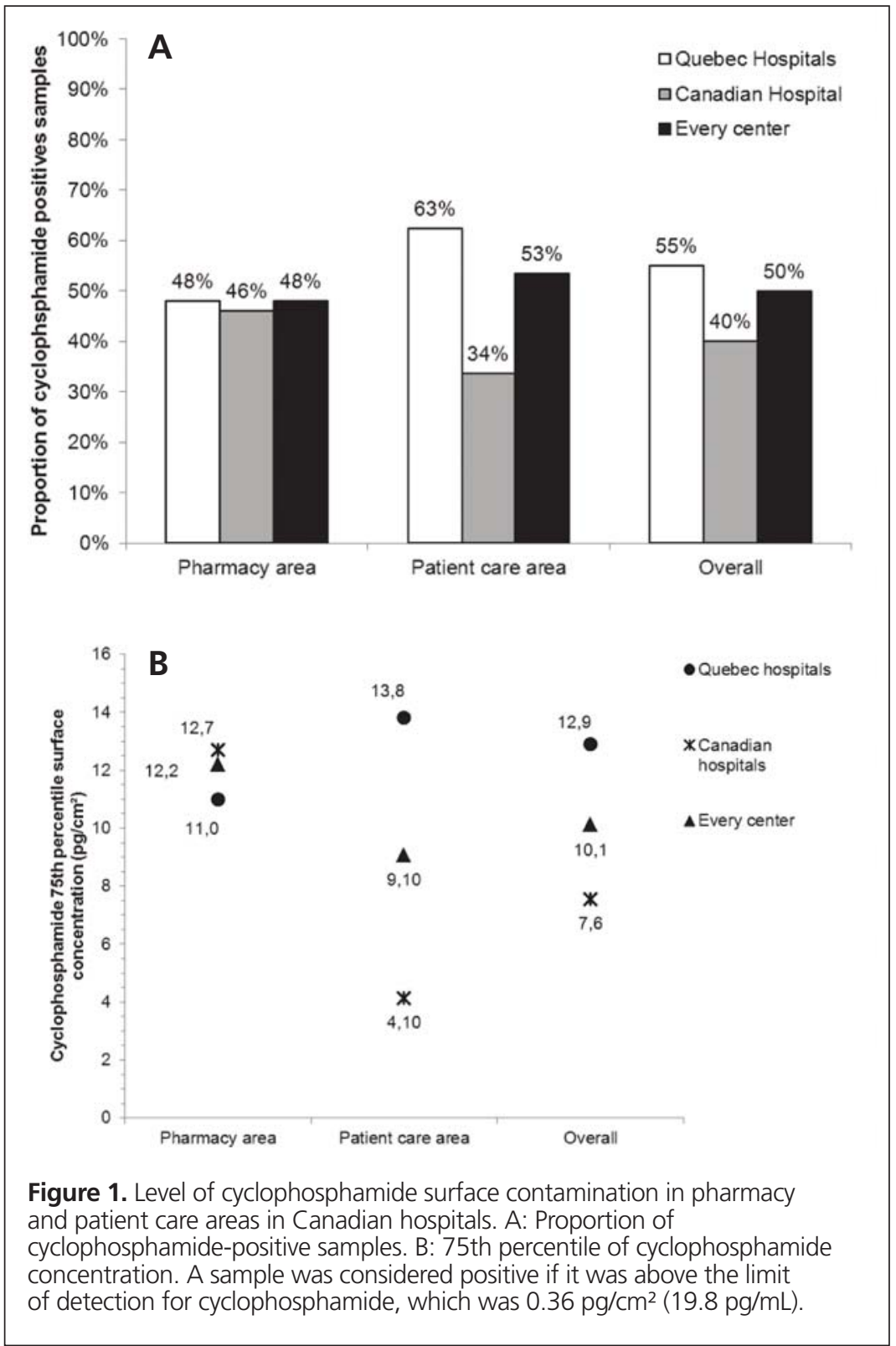

Over the years, the most frequent cyclophosphamidepositive sampling sites in the pharmacy were the front grille of the hood and the floor in front of the hood (Figure 3A). In patient care areas, the most frequent cyclophosphamide-positive sampling site was the armrest (Figure 3B).

\section{Effects of Working Practices}

The potential link between certain working practices and surface concentration with cyclophosphamide in the pharmacy was investigated. Overall, the 75th percentile for cyclophosphamide concentration was lower for centres that used a CSTD, removed the outer packaging of vials after receipt, and/or cleaned vials after receipt, but this difference was not significant (Tables 4-6).

\section{DISCUSSION}

\section{Environmental Monitoring}

Overall, among samples obtained from 51 Canadian hospitals participating in this study, $50 \%$ were positive for cyclophosphamide, $21 \%$ were positive for ifosfamide, and $9 \%$ were positive for methotrexate. The 75 th percentile values for surface concentration were $10.8 \mathrm{pg} / \mathrm{cm}^{2}$ for cyclophosphamide, $1.59 \mathrm{pg} / \mathrm{cm}^{2}$ for ifosfamide, and below the limit of detection for methotrexate. 

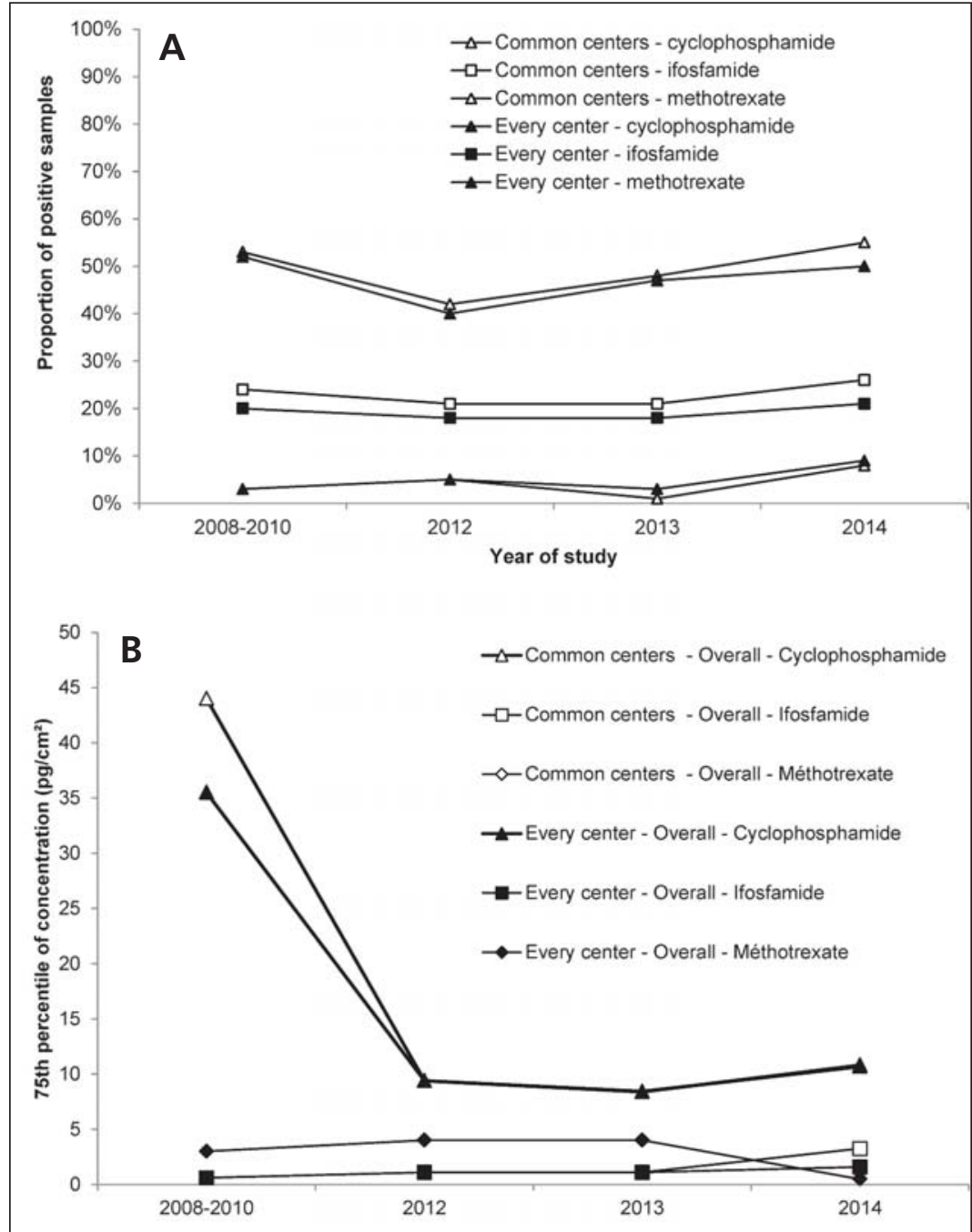

Figure 2. Surface contamination with antineoplastic drugs for the 19 "common centres" that participated in all 4 studies (the current study [2014] and 3 earlier studies [2008-2010, 2012, and 2013] $]^{10-12}$ ) and for all centres that participated in each individual study $(n=51$ in the current study and $n=25$, 33 , and 36, respectively, in the 3 earlier studies). A: Proportion of positive samples (pharmacy and patient care areas combined). B: 75th percentile of surface concentration. A sample was considered positive if it was above the limit of detection, which was $0.36 \mathrm{pg} / \mathrm{cm}^{2}(19.8 \mathrm{pg} / \mathrm{mL})$ for cyclophosphamide, $0.95 \mathrm{pg} / \mathrm{cm}^{2}$ (52 pg/mL) for ifosfamide, and $0.97 \mathrm{pg} / \mathrm{cm}^{2}(53 \mathrm{pg} / \mathrm{mL})$ for methotrexate.

Relative to 3 other multicentre studies conducted within Quebec in 2008-2010, 2012, and 2013, respectively, ${ }^{10-12}$ the proportion of positive samples in the current study remained constant. Nonetheless, the surface concentration of antineoplastic drugs measured has been decreasing over the years and seems to have reached a plateau in 2012.
This reduction in surface contamination can probably be explained by an increase in awareness of the importance of safe-handling practices, following the adoption of improved local procedures $^{8,9}$ and the publication of international guidelines. ${ }^{6,7}$ It will be interesting to find out, over the coming years, whether the new guideline for compounding hazardous drugs of the 


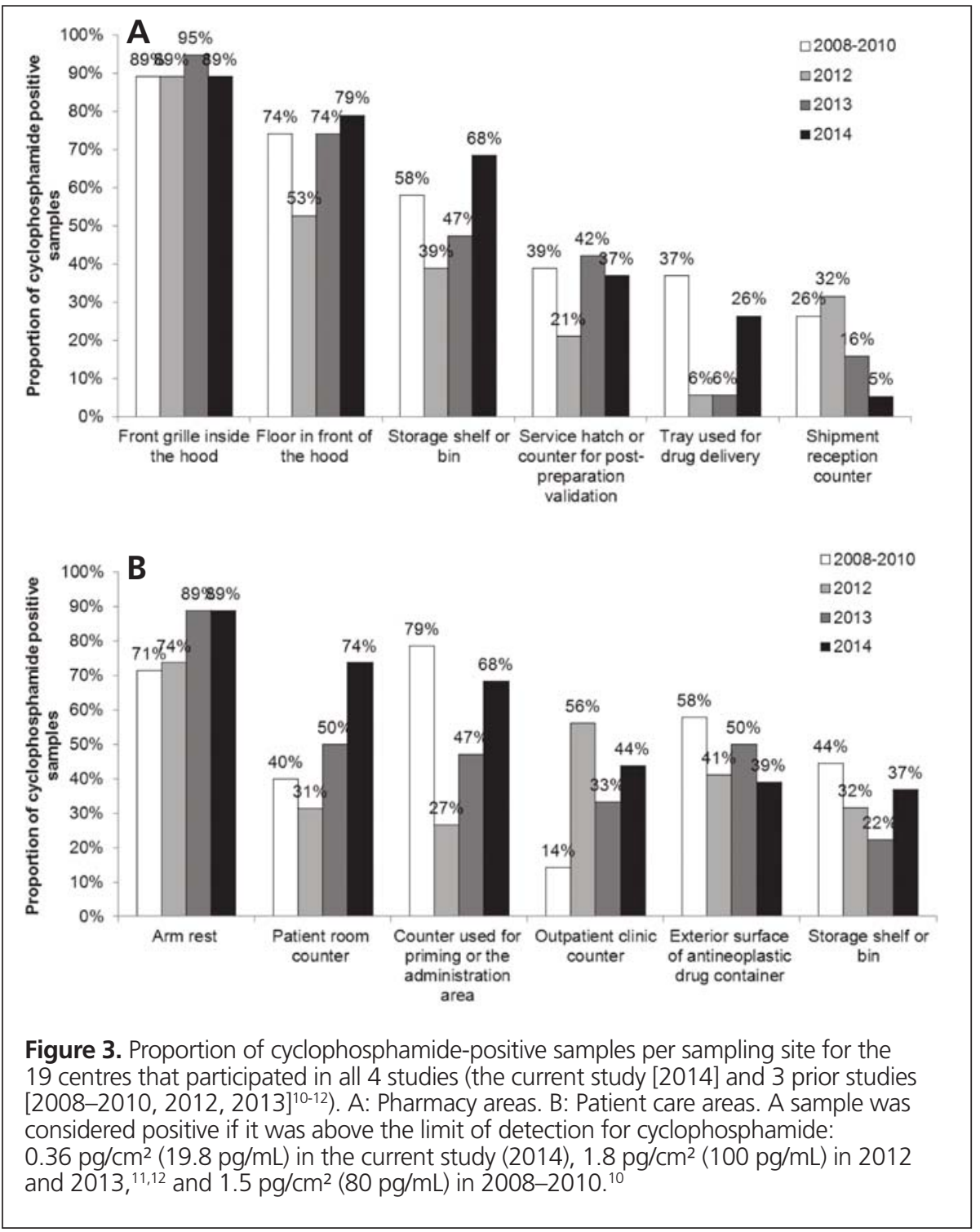

Ordre des pharmaciens du Québec ${ }^{9}$ will have an effect on surface contamination.

\section{Sampling Sites}

Over the 4 studies, the most frequent cyclophosphamidepositive sample sites were the front grille of the hood, the floor in front of the hood, and the armrest of the chair used during administration of antineoplastic drugs. Similar sites were found to be highly contaminated in another recent large study involving 30 US hospitals. In that study, Sessink and others ${ }^{16}$ found that $97 \%$ of samples from the front grille of the hood and $82 \%$ of those from the floor in front of the hood were positive for cyclophosphamide.

These frequently contaminated sites correspond to sites where large quantities of antineoplastic drugs are manipulated.
In a Canadian study, Hon and others ${ }^{17}$ identified the steps of drug preparation and drug administration as critical aspects of the medication-use system. In addition to sites where large quantities of antineoplastic drugs are manipulated, these authors found contamination on everyday objects such as pencils and door handles. ${ }^{17}$ Indeed, skin absorption and inhalation are frequent sources of contamination, but hand-to-mouth contact also leads to occupational exposure. ${ }^{3}$ In another Canadian study, Hon and others ${ }^{18}$ evaluated the contamination of hands of health care workers. They found that workers in the patient care unit who were not directly involved in drug administration, such as dieticians, ward aides, oncologists, and volunteers, had the highest rate of hand contamination, with $28.6 \%$ of this group testing positive for contamination. ${ }^{18}$

In addition to emphasizing the importance of adequate working practices and personal protective equipment, the 
Table 4. Effect of Using Closed-System Transfer Devices (CSTDs) on Contamination of Selected Sampling Sites in the Pharmacy

\begin{tabular}{|c|c|c|c|}
\hline \multirow[t]{2}{*}{ Sampling Site } & \multicolumn{2}{|c|}{$\begin{array}{l}\text { 75th Percentile of Cyclophosphamide } \\
\text { Concentration }\left(\mathrm{pg} / \mathrm{cm}^{2}\right)\end{array}$} & \multirow[t]{2}{*}{$p$ Value* } \\
\hline & CSTD in Use $(n=12)$ & CSTD Not in Use $(n=37)$ & \\
\hline Front grille inside hood & 112 & 193 & 0.40 \\
\hline Floor in front of hood & 48.6 & 82.6 & 0.43 \\
\hline $\begin{array}{l}\text { Service hatch or counter for } \\
\text { postpreparation validation }\end{array}$ & 0.182 & 3.35 & 0.41 \\
\hline Tray used for drug delivery & 0.303 & 2.44 & 0.46 \\
\hline
\end{tabular}

*Kolmogorov-Smirnov test for 2 unpaired samples.

Table 5. Effect of Removing Outer Vial Packaging on Contamination of Selected Sampling Sites in the Pharmacy

\begin{tabular}{|c|c|c|c|}
\hline \multirow[t]{2}{*}{ Sampling Site } & \multicolumn{2}{|c|}{$\begin{array}{l}\text { 75th Percentile of Cyclophosphamide } \\
\text { Concentration }\left(\mathrm{pg} / \mathrm{cm}^{2}\right)\end{array}$} & \multirow[t]{2}{*}{$p$ Value* } \\
\hline & $\begin{array}{l}\text { Removal of Outer } \\
\text { Packaging }(n=29)\end{array}$ & $\begin{array}{l}\text { No Removal of Outer } \\
\text { Packaging }(n=20)\end{array}$ & \\
\hline Storage shelf or bin & 3.90 & 3.05 & 0.41 \\
\hline Front grille inside hood & 137 & 173 & 0.50 \\
\hline Floor in front of hood & 61.9 & 94.8 & 0.48 \\
\hline $\begin{array}{l}\text { Service hatch or counter for post- } \\
\text { preparation validation }\end{array}$ & 2.89 & 4.05 & 0.50 \\
\hline Tray used for drug delivery & 0.363 & 4.32 & 0.18 \\
\hline
\end{tabular}

*Kolmogorov-Smirnov test for 2 unpaired samples.

\section{Table 6. Effect of Cleaning Vials on Contamination of Selected Sampling Sites in the Pharmacy}

\begin{tabular}{lccc} 
Sampling Site & \multicolumn{2}{c}{$\begin{array}{c}\text { 75th Percentile of Cyclophosphamide } \\
\text { Concentration }\left(\mathbf{p g} / \mathbf{c m}^{2}\right)\end{array}$} & p Value* \\
\cline { 2 - 3 } & $\begin{array}{c}\text { Cleaning of Vial Exterior } \\
(\boldsymbol{n}=\mathbf{2 8})\end{array}$ & $\begin{array}{c}\text { No Cleaning of Vial } \\
\text { Exterior }(\boldsymbol{n}=\mathbf{2 1})\end{array}$ & 0.48 \\
\hline Storage shelf or bin & 3.40 & 4.41 & 0.32 \\
Front grille inside hood & 151 & 169 & 0.32 \\
Floor in front of hood & 64.7 & 132 & 0.50 \\
Service hatch or counter for post- & 2.09 & 3.35 & 0.19 \\
preparation validation & 0.272 & 4.28 & \\
Tray used for drug delivery & & &
\end{tabular}

*Kolmogorov-Smirnov test for 2 unpaired samples.

presence of contamination highlights the usefulness of suitable cleaning methods. The use of alcohol to clean a surface can often spread the contamination, rather than eliminating it. ${ }^{19}$ The use of detergent and water is better for cleaning a surface, but to totally eliminate all traces of contaminants, decontamination should be done with a combination of sodium hypochlorite and sodium thiosulfate. ${ }^{20}$

\section{Pharmacy and Patient Care Areas}

Overall, surface contamination in the current study was similar in pharmacy and patient care areas. However, contamination of patient care areas with cyclophosphamide was higher for Quebec hospitals than for hospitals from other provinces. Although the data collected for this study were insufficient to explain this difference, it would be interesting to determine whether different practices for activities such as cleaning, drug preparation, and drug administration are used in patient care units in Quebec and the other provinces. The difference in response rates between Quebec and the rest of Canada limits this comparison, and participating hospitals may not be representative of all Canadian hospitals.

\section{Effects of Working Practices}

Subanalyses were performed to evaluate the effect of 3 working practices: use of a CSTD, removal of packaging, and cleaning of vials after initial receipt. No statistically significant differences were found between hospitals that did and did not follow these practices. In the 2013 study, ${ }^{12}$ the concentration of contaminants 
was lower on the front grille of the hood at centres that used CSTDs, removed the outer packaging, and cleaned vials after receipt. Even though numerous studies have shown that CSTDs can reduce contamination, their use does not completely eliminate contamination. For instance, Sessink and others ${ }^{16}$ found a median of $1.69 \mathrm{ng} / \mathrm{cm}^{2}$ (or $1690 \mathrm{pg} / \mathrm{cm}^{2}$ ) of cyclophosphamide on the front grille of the hood before CSTDs were in use and $0.39 \mathrm{ng} / \mathrm{cm}^{2}$ (or $390 \mathrm{pg} / \mathrm{cm}^{2}$ ) after CSTDs were implemented. In the current study, the median concentration of cyclophosphamide on the front grille of the hood was $43 \mathrm{pg} / \mathrm{cm}^{2}$ at hospitals not using a CSTD $(n=12)$ and $15 \mathrm{pg} / \mathrm{cm}^{2}$ at hospitals that did use such devices $(n=37)$. As such, hospitals in this study that did not use CSTDs had a 26-fold lower concentration of cyclophosphamide than hospitals in other studies that did use CSTDs $\left(15 \mathrm{pg} / \mathrm{cm}^{2}\right.$ versus $390 \mathrm{pg} / \mathrm{cm}^{2}$ ). The very low surface contamination observed in the current multicentre study, despite the fact that few participating hospitals (12/49) reported the use of CSTDs, indicates that many strategies can contribute to a low level of surface contamination.

It is recommended that vials be unpacked and cleaned after initial receipt. ${ }^{8}$ Although we did not find a significant difference between hospitals that did and did not follow this practice, this low-cost solution can probably help to reduce contamination, given that the exterior surface of vials is often contaminated during the manufacturing process. ${ }^{21}$

\section{Implications for Practice}

As long as no health-based safe limit of exposure is known, workers' exposure to antineoplastic and other hazardous drugs should be kept as low as reasonably achievable. We suggest the use of local (country- or region-specific) and attainable goals and recommend that centres strive to attain a level of contamination lower than these targets. For each drug, the value of the most recent global 75th percentile (derived from all centres that participated in the current study) should be used as a manageable target for Canadian hospitals. It is hoped that these target values will continue to be reduced over the years to come.

How can hospitals reduce their level of contamination? Environmental sampling can help to identify problem areas, which can then be cleaned thoroughly with a combination of sodium hypochlorite and sodium thiosulfate. Such cleaning should be done regularly, and a log should be signed by the workers responsible, especially for areas where large quantities of antineoplastic agents are manipulated (e.g., the hood in the pharmacy) and areas that are touched frequently (e.g., armrests). The source of the contamination may be the exterior of vials, so cleaning vials when they are received and cleaning the container for the compounded product once prepared can also limit contamination. Materials that cannot be cleaned properly should be substituted with materials that can be cleaned, if possible.

Finally, it is important to continue raising the awareness of all workers who are potentially exposed to antineoplastic drugs, to ensure that they use proper working practices that will limit the spread of contamination and that they adequately protect themselves with personal protective equipment. ${ }^{8}$

\section{Strengths and Limitations}

This study was the largest multicentre study of hazardousdrug contamination to date in Canadian hospitals and provides results for both pharmacy and patient care areas. To limit technical bias and to ensure a consistent sampling method across all centres, the investigators supplied a video demonstrating the correct sampling technique. As much as possible, sampling was performed at the end of the day, to generate values that were representative of a working day and also representative of the potential professional exposure to these drugs among health care workers. However, all sampling at each institution was performed on a single day, and different results might have been obtained on a different day. Many different analytical techniques are available, so caution should be used when comparing these results with the results of other studies. The limits of detection were comparable to those used by other investigators. The global recovery rate from surfaces was adequate; however, the recovery from linoleum (floors) was lower, so those results might be underestimations. The cost of the analysis may have prevented some hospitals from participating.

\section{CONCLUSIONS}

Relative to 3 other multicentre studies conducted in Quebec over the past several years, the proportion of positive samples remained constant. Nonetheless, the 75 th percentile surface concentration of antineoplastic drugs has been decreasing over time and seems to have reached a plateau. As long as no healthbased limit of exposure is known, local (country- or regionspecific) and attainable goals for surface contamination with hazardous drugs should be set annually.

\section{References}

1. Medical surveillance for healthcare workers exposed to hazardous drugs. Cincinnati $(\mathrm{OH})$ : Department of Health and Human Services (US) Centers for Disease Control and Prevention, National Institute for Occupational Safety and Health; 2012 [cited 2013 Oct 15]. Available from: www.cdc.gov/niosh/docs/wp-solutions/2013-103/pdfs/2013-103.pdf

2. Dranitsaris G, Johnston M, Poirier S, Schueller T, Milliken D, Green E, et al. Are health care providers who work with cancer drugs at an increased risk for toxic events? A systematic review and meta-analysis of the literature. J Oncol Pharm Pract. 2005;11(2):69-78.

3. Connor TH, Lawson CC, Polovich M, McDiarmid MA. Reproductive health risks associated with occupational exposures to antineoplastic drugs in health care settings: a review of the evidence. J Occup Environ Med. 2014;56(9):901-10.

4. Preventing occupational exposure to antineoplastic and other hazardous drugs in healthcare settings. Publ No. 2004-165. Cincinnati (OH): Department of Health and Human Services (US), Centers for Disease Control and Prevention, National Institute for Occupational Safety and Health; 2004 [cited 2014 Oct 24]. Available from: www.cdc.gov/niosh/docs/2004-165/

5. Connor TH, MacKenzie BA, DeBord DG, Trout DB, O'Callaghan JP. NIOSH list of antineoplastic and other hazardous drugs in healthcare settings, 2014. Cincinnati (OH): Department of Health and Human Services (US) 
This single copy is for your personal, non-commercial use only.

For permission to reprint multiple copies or to order presentation-ready copies for distribution, contact CJHP at cjhpedit@cshp.ca

Centers for Disease Control and Prevention, National Institute for Occupational Safety and Health; 2014 [cited 2014 Oct 24]. Available from: www.cdc.gov/niosh/docs/2014-138/pdfs/2014-138.pdf

6. American Society of Health-System Pharmacists. ASHP guidelines on handling hazardous drugs. Am J Health Syst Pharm. 2006;63(12):1172-93.

7. $<800>$ Hazardous drugs_-handling in healthcare settings [briefing]. Rockville (MD): U.S. Pharmacopeial Convention; 2014 [cited 2014 Oct 24]. Available from: www.usp.org/sites/default/files/usp_pdf/EN/ m7808.pdf

8. Prevention guide — safe handling of hazardous drugs. Montréal (QC): Association paritaire pour la santé et la sécurité du travail du secteur des affaires sociales; 2008 [cited 2014 Oct 24]. Available from: www.asstsas.qc.ca/ publications/publications-specialisees/guides-de-prevention/preventionguide-safe-handling-of-hazardous-drugs.html

9. Norme 2014.02 : Préparation de produits stériles dangereux en pharmacie. Montréal (QC): Ordre des pharmaciens du Québec; 2014 [cited 2014 Mar 20]. Available from: www.opq.org/fr-CA/publications/normes-de-pratiqueet-lignes-directrices/

10. Bussières JF, Tanguay C, Touzin K, Langlois É, Lefebvre M. Environmental contamination with hazardous drugs in Quebec hospitals. Can J Hosp Pharm. 2012;65(6):428-35.

11. Merger D, Tanguay C, Langlois E, Lefebvre M, Bussières JF. Multicenter study of environmental contamination with antineoplastic drugs in 33 Canadian hospitals. Int Arch Occup Environ Health. 2014;87(3):307-13.

12. Berruyer M, Tanguay C, Caron NJ, Lefebvre M, Bussières JF. Multicenter study of environmental contamination with antineoplastic drugs in 36 Canadian hospitals: a 2013 follow-up study. J Occup Environ Hyg. 2015;12(2):87-94.

13. Larson RR, Khazaeli MB, Dillon HK. Monitoring method for surface contamination caused by selected antineoplastic agents. Am J Health Syst Pharm. 2002;59(3):270-7.

14. Article 5: calculation of mean values. In: Commission directive 2009/90/CE of 31 July 2009 laying down, pursuant to Directive 2000/60/EC of the European Parliament and of the Council, technical specifications for chemical analysis and monitoring of water status. Official Journal of the European Union. Brussels (Belgium): European Union; 2009 [cited 2014 Oct 24]. Available from: http://eur-lex.europa.eu/LexUriServ/ LexUriServ.do?uri=OJ:L:2009:201:0036:0038:EN:PDF

15. Hornung RW, Reed LD. Estimation of average concentration in the presence of nondetectable values. Appl Occup Environ Hyg. 1990;5(1):46-51.

16. Sessink PJ, Trahan J, Coyne W. Reduction in surface contamination with cyclophosphamide in 30 US hospital pharmacies following implementation of a closed-system drug transfer device. Hosp Pharm. 2013;48(3):204-12.

17. Hon CY, Teschke K, Chu W, Demers P, Venners S. Antineoplastic drug contamination of surfaces throughout the hospital medication system in Canadian hospitals. J Occup Environ Hyg. 2013;10(7):374-83.
18. Hon CY, Teschke K, Demers PA, Venners S. Antineoplastic drug contamination on the hands of employees working throughout the hospital medication system. Ann Occup Hyg. 2014;58(6):761-70.

19. Chu WC, Hon CY, Danyluk Q, Chua PP, Astrakianakis G. Pilot assessment of the antineoplastic drug contamination levels in British Columbian hospitals pre- and post-cleaning. J Oncol Pharm Pract. 2012;18(1):46-51.

20. Touzin K, Bussières JF, Langlois E, Lefebvre M, Métra A. Pilot study comparing the efficacy of two cleaning techniques in reducing environmental contamination with cyclophosphamide. Ann Occup Hyg. 2010;54(3):351-9.

21. Schierl R, Herwig A, Pfaller A, Groebmair S, Fischer E. Surface contamination of antineoplastic drug vials: comparison of unprotected and protected vials. Am J Health Syst Pharm. 2010;67(6):428-9.

Alexia Janes is a Research Assistant in the Pharmacy Practice Research Unit and the Pharmacy Department, Centre hospitalier universitaire SainteJustine, Montréal, Quebec. She is also a DPharm candidate with the Faculté des sciences pharmaceutiques et biologiques de Lille, Lille, France.

Cynthia Tanguay, BSc, MSc, is a Research Assistant in the Pharmacy Practice Research Unit and the Pharmacy Department, Centre hospitalier universitaire Sainte-Justine, Montréal, Quebec.

Nicolas J Caron, $\mathrm{PhD}$, is a Biochemist with the Centre de toxicologie du Québec, Institut national de santé publique du Québec, Québec, Quebec

Jean-François Bussières, BPharm, MSc, MBA, FCSHP, is Director of the Pharmacy Practice Research Unit and the Pharmacy Department, Centre hospitalier universitaire Sainte-Justine, and a Clinical Professor, Faculty of Pharmacy, Université de Montréal, Montréal, Quebec.

Competing interests: None declared.

\section{Address correspondence to:}

Jean-François Bussières

Pharmacy Department

Centre hospitalier universitaire Sainte-Justine

3175, chemin de la Côte Sainte-Catherine

Montréal QC H3T 1C5

e-mail: jf.bussieres@ssss.gouv.qc.ca

Acknowledgements: The authors would like to thank the 51 health care centres that participated in the 2014 study.

Funding: No funding was received for this study. 